IZA DP No. 8478

The Family Gap in Career Progression

Astrid Kunze

September 2014

Forschungsinstitut zur Zukunft der Arbeit Institute for the Study of Labor 


\title{
The Family Gap in Career Progression
}

\author{
Astrid Kunze \\ NHH Norwegian School of Economics \\ and IZA
}

\section{Discussion Paper No. 8478 \\ September 2014}

\author{
IZA \\ P.O. Box 7240 \\ 53072 Bonn \\ Germany \\ Phone: +49-228-3894-0 \\ Fax: +49-228-3894-180 \\ E-mail: iza@iza.org
}

\begin{abstract}
Any opinions expressed here are those of the author(s) and not those of IZA. Research published in this series may include views on policy, but the institute itself takes no institutional policy positions. The IZA research network is committed to the IZA Guiding Principles of Research Integrity.

The Institute for the Study of Labor (IZA) in Bonn is a local and virtual international research center and a place of communication between science, politics and business. IZA is an independent nonprofit organization supported by Deutsche Post Foundation. The center is associated with the University of Bonn and offers a stimulating research environment through its international network, workshops and conferences, data service, project support, research visits and doctoral program. IZA engages in (i) original and internationally competitive research in all fields of labor economics, (ii) development of policy concepts, and (iii) dissemination of research results and concepts to the interested public.
\end{abstract}

IZA Discussion Papers often represent preliminary work and are circulated to encourage discussion. Citation of such a paper should account for its provisional character. A revised version may be available directly from the author. 


\section{ABSTRACT}

\section{The Family Gap in Career Progression*}

This study investigates whether and when during the life cycle women fall behind in terms of career progression because of children. We use 1987-1997 Norwegian panel data that contain information on individuals' position in their career hierarchy as well as a direct measure of their promotions. We measure overall promotions as increases in rank within the same establishment as well as in combination with an establishment change. Women with children are 1.6 percentage points less likely promoted than women without children; this is what we refer to as the family gap in climbing the career. We find that mothers tend to enter on lower ranks than non-mothers. 37 percent of the gap can be explained by rank fixed effects and human capital characteristics. A large part remains unexplained. Graphical analyses show that part of the difference already evolves during the early career. Part of this seems related to the relatively low starting ranks.

JEL Classification: J1, J6, M5

Keywords: promotion, women, family gap, human capital, organizational hierarchy, decomposition

Corresponding author:

Astrid Kunze

$\mathrm{NHH}$ Norwegian School of Economics

Helleveien 30

5045 Bergen

Norway

E-mail: Astrid.Kunze@nhh.no

\footnotetext{
* The author gratefully acknowledges the comments by the editors, two anonymous referees, Amalia R. Miller, Øivind A. Nilsen, Kai Liu, Vanessa Dräger, colleagues at IZA and participants at the IZA Workshop on Gender Convergence in Bonn in April 2014. Kunze is grateful to the Research Council of Norway and the E.ON Ruhrgas Fund for financial support. All remaining errors are the author's own responsibility.
} 


\section{Introduction}

Trends over the previous 50 years in wages of men and women demonstrate the strong convergence in wages leading to a reduction in the gender wage gap (see Jacobsen, 2014 this volume). The more recent 20 years, however, show that the gender wage gap has stalled at a significant and positive level. The level varies across the OECD countries. For Germany the gap is quite high, 23 percent, and for Norway and the other Scandinavian countries it is lowest, 15 percent. Studies using data on male and female workers since first entry into the labor market have shown that men and women with the same education tend to enter at similar wage levels, but wages begin to diverge during the early career (Manning and Swaffield, 2008; Fitzenberger and Kunze, 2005). The male-female wage divergence increases substantially more after childbirth which can partly be related to work interruptions and reduced hours of work (Mincer and Polachek, 1974; Bertrand et al. 2010).

International studies have also shown that women with children earn less at the mean than childless women; this is often referred to as the family gap in pay (e.g. Harkness and Waldfogel, 1999). Previous evidence suggests that the family gap in pay develops in three phases. Women who will have children at some point in their lives enter at lower wages into the labor market (Lundberg and Rose, 2000). Mothers fall behind other women because of the drop in wages when they return to work following childbirth. ${ }^{1}$ In addition, several studies found that mother's returns to experience are lower than before first childbirth and compared to non-mothers.

Overall empirical evidence shows that women's career progress is delayed or diminished because of children. Looking at the literature it is however noticeable that most of the longitudinal evidence is based on indirect measures of career progress or success such as individual wage growth or wage levels. This paper contributes to this literature by presenting

\footnotetext{
${ }^{1}$ A drop in wages is consistent with a human capital framework, as is predicted in Polachek (1975).
} 
new evidence on the family gap in career progress using a direct measure of career success. We use 1987-1997 Norwegian panel data that contain information on individuals' position in their career hierarchy and allow us to measure promotions. We investigate the difference in promotion probability of women with and without children where promotions can take place internally within an establishment or in connection with a change of employer.

The family pay gap may partly capture that women do not receive internal promotions or better positions when they move firms (external promotions). Existing research based on surveys such as the NLSY does not contain information on the hierarchies of firms and the position in the hierarchy the worker has. Hence, with such data we cannot measure whether promotion probabilities within rank are lower for mothers than for non-mothers. The panel data we use in this study contain detailed hierarchical information and cover the population of white collar workers in private sector establishments in Norway.

The promotion of women more generally has not received much attention in the labor economics literature so far. But this is an important question in the debate why women are underrepresented in top management positions. Knowledge about promotions of women can also contribute to a deeper understanding of the remaining residual gender wage gap. Promotions are an important determinant of the returns to skills and hence can indirectly affect the decision to participate in the labor market. Women's participation in the labor market is becoming of increasing importance in times of dramatic demographic changes particularly in the European economies.

The remainder of the paper is organized as follows. Section two surveys explanations of the family wage gap and the hypotheses that we will explore. Section three provides institutional background on Norway. Section four describes the data and presents descriptive statistics. Section five presents the empirical results. Section six concludes. 


\section{The family gap in wages and careers}

A number of studies investigated the impact of maternity leave and having children on the individual wage process. The most common approach to analyze the wage effect of having children has been to compare the wages of women with children to those of childless women holding productivity related characteristics constant. These include human capital characteristics, such as education and actual work experience, and parental leave as well as demographic variables that serve as proxies for leave taking. The difference in wages is often called the family gap.

International studies find that the family gap varies across countries (Harkness and Waldfogel, 1999; Davies and Pierre, 2005; Dupuy and Kranz-Fernandez, 2011). ${ }^{2}$ In country studies a significant family gap is found for the US (see Anderson, Binder and Krause, 2002; Waldfogel, 1998), for the UK (see Joshi, Paci and Waldfogel, 1999) and for Canada (see Phipps, Burton and Lethbrigde, 2001). For Norway, Hardøy and Schøne (2008) showed a moderate family gap. For the first child they found a decrease in wages of 1.4 percent that increases to 4 percent for the third child. Their estimates of the family wage gap are larger for the private sector than for the public sector. ${ }^{3}$ No evidence of a family gap is found for Denmark (Datta Gupta and Smith, 2002; Simonsen and Skipper, 2012) and for Sweden (Albrecht et al., 1999).

In this literature a number of hypotheses have been pursued to explain the family gap. Women typically interrupt work for a period after childbirth (Waldfogel, 1998). This implies a loss in terms of years of actual work experience compared to other workers of the same age. Interruptions may also have negative effects on earnings due to depreciation of human capital

\footnotetext{
${ }^{2}$ Estimates of the family gap are difficult to compare across countries because of different data sources and definitions. Harkness and Waldfogel (1999) is the most comprehensive cross-country study using the Luxembourg Income study (LIS). They find that the raw family gap among full-time workers varies between 1.4 percent for Australia and 9.4 percent for Germany.

${ }^{3}$ Petersen, et al. (2010) found that for the private sector the within-job family gap is not significant suggesting that segregation on occupation and establishment are important explanatory factors.
} 
(Mincer and Polachek, 1974; Albrecht et al., 1999). Such effects are expected to be relatively strong in technology intensive occupations. ${ }^{4}$ In addition to human capital effects through observed factors, heterogeneity in terms of unobserved characteristics, or unobserved ability, may explain part of the family gap too if these factors are correlated with fertility (Lundberg and Rose, 2000; Simonsen and Skipper, 2012). Non-random selection into sectors and type of jobs may also be related to the observed mother-non-mother earnings difference if for example high and low wage jobs differ in terms of family friendliness or other non-monetary characteristics (Joshi et al., 1999; Datta Gupta and Smith, 2000; Nielsen et al., 2004), Felfe, 2012). Not all women return to work for an extended period post-childbirth and the selection of returning women may not be random which will also bias the family gap (Ejrnæs and Kunze, 2013).

Other factors that may explain the relatively low earnings of mothers can be related to low mobility of mothers and that women with children remain in low worker-job matches (Waldfogel, 1998; Phipps et al., 2001). If mothers are less likely to search for new jobs because of high search costs, for example, they may remain in jobs that are a bad match and only slowly improve the quality of their job match. Evidence shows that young women both in the US and Germany search longer for a job than men after an exogenous plant closure (Kunze and Troske, 2012; Kunze and Troske, 2014). This leads to lower earnings compared to similar childless women. Since the fertility period often clashes with the early career, the loss due to motherhood might depend on the timing of childbirth in relation to the labor market career. Related to this point, Waldfogel (1998) and Phipps et al. (2001) find that returning to the same employer after maternity leave actually has a positive effect on wages, but this might be because staying with the same employer actually acts as a kind of insurance against income loss. Waldfogel (1998) also finds that the size of wage loss due to taking

\footnotetext{
${ }^{4}$ In an earlier study, Polachek (1981) showed evidence of considerable variation of the depreciation rate across different occupations.
} 
maternity leave depends on whether the woman was covered by a maternity leave scheme. Most of this literature does not fully account for the endogeneity of fertility decisions to the wage process (Heckman and Walker, 1990). Exceptions are Angrist and Evans (1998), Hotz et al. (2005) and Miller (2011) that use plausibly exogenous instruments to separate the effects at selected parity. Even after controlling for a lot of these factors many studies still find the significant drop in wages after childbirth. This might be interpreted as employer discrimination.

Another interpretation of the earnings drop we observe post-childbirth or the lower relative earnings of women with children compared to women without children is that women are downgraded in terms of career levels post-childbirth. When looking at the mean earnings growth in the period post-childbirth we observe that a woman never returns to her prechildbirth earnings growth path. This implies that rebound effects are not sufficiently strong (see e.g., Jacobsen et al., 1995).

The family pay gap literature indicates that women cannot continue on the career progress they made before first becoming a mother, and when they return to work after childbirth they have to start from a lower level. In fact they may never return to the career path during the very early career. This might be because they step down in terms of occupation. The literature on the question whether women step down in terms of career or occupation is scarce.

Recent exceptions are Manning and Petrongolo (2008) and Conolly and Gregory (2008) showing that part-time work leads to downgrading in terms of occupation. Since parttime is often used by women to reconcile work and family, this finding is relevant for the post-childbirth period. Ejrnæs and Kunze (2013) also found a dip in earnings 1-2 years actually before having the first work interruption related to childbirth. An explanation could be that women downgrade their career already before becoming a mother. Studies showing a 
positive entry earnings differential between childless women and others suggest further that from the beginning of careers women who will become a mother later in life sort into different career tracks (Mincer and Polachek, 1974). Related is also the question of promotions and what determines promotions. Promotions can be viewed as the outcome of internal tournaments, external labor markets and human capital investments (see Gibbons and Waldman, 1999 for an overview). Since women often work part-time around childbirth or take periods of leave they may as well experience relatively less job promotions. This may vary across occupations and Goldin (2014) made the point that the flexibility in terms of working hours alongside other dimensions plays an important role in understanding women's relatively lower positions in the labor market.

This study contributes to this literature by analyzing direct career outcomes for women followed over time in the private sector. We model career promotions as linear regressions where the dependent variable is a binary variable that is equal to one if the change in rank between period $t$ and $t+1$ is positive and zero otherwise. The main explanatory variables are human capital characteristics measured in period t, but we also use establishment characteristics and fixed effects. We use information from Norwegian employer-employee register data merged with survey data that allow us to construct a direct measure of career progression - promotions on job ladders. Using these data we will investigate the following selected hypotheses related to career breaks explaining family gap:

I. Do women who have children start on different ranks than women who do not have children?

II. Is there a family gap in career progress when we use overall promotions?

III. Are women promoted less likely after having children than comparable women?

IV. Does the family gap in promotions arise after having children, or already before? 
The analysis builds on the detailed information of occupations and ranks and the fact that we observe the population of white collar workers in a large sample of enterprises. Estimations build on the family pay gap literature.

\section{Background}

In this section we describe main Norwegian institutions relevant as background for work and family: working hours and part time work, the provision of parental leave and child care for pre-school children and children in primary school.

The typical worker in Norway works 5 days a week and 37.5 hours per week. Part time work is common among women with young children; not so for men. Norway has a generous parental leave system where part of the parental leave is reserved to the mother; that is 3 weeks before childbirth and 6 weeks after childbirth. In 1987, the first year of our observation window, parents could take in total 100 days after birth paid leave from work. Except the 6 weeks after childbirth, parents can share the leave; but in practice it was mothers taking leave from work. Gradually from 1989 to 1993 the duration of total parental leave (incl. maternity leave) was expanded. In 1992 the duration amounted to 165 days.

An important reform took action on 1 April 1993 when leave was extended to 42 weeks (=294 days) of paid leave with the choice to receive 100 per cent wage compensation when one takes 42 weeks of leave, or 80 percent when one takes 52 weeks. In order to be eligible the mother has to be employed during 6 out of 10 months immediately prior to birth. ${ }^{5}$

Another aspect that makes the 1993 reform remarkable is the introduction of 4 weeks of paid leave that were reserved for the father and could normally be not transferred to the mother. Hence, if the couple chooses 42 weeks of leave, then $29(=42-6-3-4)$ weeks of leave can be freely shared between the mother and father. If the father would not use the 4 weeks

\footnotetext{
${ }^{5}$ Until 1993 leave could only be taken full-time, that was modified in 1994. Otherwise the law of 1993 has been in place unchanged until 2005.
} 
the total benefits to the couple would be reduced by those 4 weeks. The 1993 reform was rather interesting since until 1993 virtually no father (3-5 per cent) in Norway took any parental leave and all went to the mother. In 1993 the take up by fathers of leave jumped to 33 per cent and this proportion steadily increased to 85 per cent by 1998. The average duration of leave is 24 days and has remained stable during this period (Lappegård, 2008). The change in father's leave has therefore been small and little consequence for our analysis.

During the period 1987 to 1997 publicly subsidized child care was not available for everybody. In the 1970s the government decided that the goal is to expand child care to full coverage but this goal was not reached for 1 to 6 years old before 2006. In 1987 approx. 11 per cent of 1-2 years old went to public child care and 44 per cent of the 3-7 years old. Until 1997, children started school at age 7. Towards the end of our observation period coverage has significantly increased to 21 per cent for the 1-2 years old and 47 per cent for the older pre-school children. These are only official numbers for use of public child care mostly organized in kindergartens. In addition, a substantial fraction of parents used nannies (dag mamas) for child care and those informal forms of childcare did not receive a public subsidy. Overall, the provision of parental leave and child care provide fairly good conditions by international standard to combine family and work. It is less clear however whether these are also good conditions for women climbing to top positions, and breaking the glass ceiling. Our analysis provides some pieces of evidence towards this question.

During the period of observation 1987 to 1997, Norway underwent a recession until 1993 when unemployment peaked at 6.7 per cent and decreased to approx. 3 percent by 1997. Throughout this period labor force participation rates remained high for men, 74-80 percent. For women LFP was 63 percent in 1987 and increased to 67 percent in 1997 (Source: SSB AKU data - the Norwegian labor force survey). 


\section{Data description and summary statistics.}

For the empirical analyses, we use the Norwegian matched employer-employee register data for white collar workers combined with information on ranks within the establishment hierarchy. This particular variable was constructed from information in an establishment level survey conducted by the NHO (Næringslivets Hovedorganisasjon - Confederation of Norwegian Enterprise) and is available for the population of white collar employees within establishments that are members of NHO. The members are in the private sector, including manufacturing, construction and machinery, oil, transport, and hotels and restaurants. The NHO data covers a large part of the private sector. NHO firms tend to be larger and older than the average private sector firm in Norway. Employees tend to be more educated and hence earn on average more.

The data are yearly and the analysis period in this study is from 1987 until 1997, which is the longest period for which all of the key variables are available. ${ }^{6}$ During this period we follow workers born between 1936 and $1969^{7}$ and we only use white collar workers. There are very few female blue collar workers in these sectors. Workers are followed over the entire period if they are employed with one of the establishments in the NHO data. In this data sample approximately 30 per cent of all workers are women.

Variables that we use in the analyses are the individual characteristics age, educational attainment in years, whether an individual has children or not and the timing of first childbirth $^{8}$, establishment identifier and characteristics such as sector and size which we measure by the number of white collar workers at the establishment in year $t$. The variable earnings per hour is constructed from information in the register data on monthly earnings and

\footnotetext{
${ }^{6}$ Before 1987, only limited register information is available from Statistics Norway. After 1997, the NHO ceased collecting the data.

${ }^{7}$ The birth cohorts 1936 to 1969 are those who can potentially be followed during the 10 year observation window.

${ }^{8}$ Since for the analysis of the family gap we will compare mothers versus non-mothers all women with and without children add to these groups. Note that only for a sub-sample we observe a first childbirth during the observations window.
} 
from the survey on normal hours of work. The normal hours of work exclude overtime hours, and earnings are from work and benefit claims excluding overtime payments. Education is defined as the years of completed education. Part-time work is defined as less than 37 hours of work per week. The year of birth of the first child is generated from the birth register where for every individual in Norway all births are reported. We count years of experience as the accumulated number of actual years of work and tenure as these within the same establishment.

The summary statistics for our data sample are presented in Table 1 . We find that mothers are older at the mean than childless women. This reflects that we use the current number of children, not completed fertility, which is in line with the literature on family gap. Women with children are much more likely to work part-time than the average woman, 33 percent compared to 26 percent. This is also reflected in the exact hours of contracted work. Women with children have accumulated more work experience and tenure.

To measure career progress on the job ladder we use seven ranks that define the hierarchy and are applied to every establishment in our sample. The variable is constructed from detailed job descriptions of 6 occupational groups. For each of the occupational groups up to seven hierarchical ranks are distinguished. The 6 occupational groups cover: technical white-collar, manager, administrative, task in shop, in storage and others. Within each occupational group, task levels (ranks) are distinguished starting with unskilled work, routine type of jobs on the lowest rank and positions with great responsibility and skill requirements on the top rank. In total there are 22 occupation-ranks which pre-define our cells. These are merged by us into 7 ranks where we use the information on tasks, responsibilities etc. in the detailed job descriptions. ${ }^{9}$ In the resulting hierarchy grid of 7 ranks, the highest rank (rank 7)

\footnotetext{
${ }^{9}$ A similar definition was first used in Hunnes, et al. (2009) who investigate the structure of wages in Norway. For further details on the definition of ranks and the measurement of promotions see Kunze and Miller (2014). Kunze and Miller (2014) focus on gender differences in promotions and gender spillover effects across ranks. This study has a different focus on family gap and the use of the
} 
includes technical directors and leading positions. On rank six, for example, chief engineers and plant managers are located. The decrease of the rank on the job ladder reflects that the complexity of tasks, responsibility and leadership task responsibilities decline as well. On rank 2, for example, technicians and cashiers are located. The lowest rank (rank 1) contains only unskilled, more routine tasks in technical and clerical fields. This hierarchy grid that matches the information on occupational groups and ranks to hierarchy ranks is then merged to the employer-employee matched data in which we follow workers from year to year during the 10 year window.

An advantage of our data is that the seven ranks are consistently defined across establishments and time within establishments. ${ }^{10}$ Hence, we can exploit the panel data to observe how workers change rank. We define a promotion or move up the career ladder of a worker as an increase in the observed rank from year-to-year ${ }^{11}$; we refer to this as an overall promotion in the following. This measure accounts for within establishment move up the career ladder as well as between establishment changes. The comparison group contains those staying on the same rank and those with a decrease of the rank. ${ }^{12}$

As Table 1 shows at the mean 6.3 percent of women are promoted per year if we count both internal promotions and promotions related to an establishment change. The promotion probability is significantly lower for women with children, 5.6 percent. This is the family gap in career progress that we are going to explore. If we would only count internal promotions

Oaxaca-Blinder decomposition in order to investigate the factors that explain the family gap. While this study focuses entirely on overall promotions, as a measure of career progress, Kunze and Miller (2014) also investigate internal promotions.

${ }^{10}$ Other studies, such as in the field of personnel economics, usually have such information only for a single (large) plant. Further, while studies using representative surveys, like the British Household Panel Survey (BHPS), rely on multiple firm data, they often observe only one worker for every firm. See, for example, Francesconi (2001) and Booth et al. (2003).

${ }^{11}$ In this study, we only use this defintion of promotion. We acknowledge that the measure depends on observed rank changes. Wage increases within rank are not labelled as a promotion.

${ }^{12}$ As we see from the promotion regressions, rank increases accrue not simply on the base of seniority rules, but many of the factors we control for have a significant impact on promotions. This is in line with theory that predicts that human capital, external labor market factors, and tournaments affect promotion decision outcomes. 
then the probability of career success would decrease by approximately 15 percent, and a family gap would remain. In the following we will focus on the more comprehensive definition of career success based on overall promotions. The data show that most of the workers (87 percent on average) stay on the same rank from year to year. Moves down the career ladder are rare, but more common the higher the rank is.

The employer characteristics reported in Table 1 show that the mean number of white collar workers in the establishments is 18 . Note that not all of the establishments have 7 ranks and the depth of organization varies across establishments and industries. At the mean across establishments, the top rank is 3 and the lowest rank 1.6.

\section{Empirical results}

\subsection{The starting position of women's careers}

A potential explanation for women with children doing worse than women without children is that they start on lower positions when they first enter the labor market. These positions may offer more flexibility in terms of hours of work, for example, but also fewer opportunities for earnings gains and promotions.

We define the entry position as the first job in the labor market after completion of education as we observe it in the data. However, we cannot observe the entry position for every individual in our sample since the observation window only covers a 10 year period and many have entered the labor market before they enter our data set. In order to have a large sample of individuals we use all first observations where the individual is younger than 30 years of age.

In Table 2 we show the distribution across entry ranks and main mean characteristics within each rank by motherhood status. Out of 18079 women in our sample 72 percent women have no children at this stage and 28 percent have children. The distribution of 
women across entry ranks shows that more than 50 percent are on the two lowest ranks. The proportion of women with children is slightly higher on those positions, 58 percent. On rank 3 we find 32.8 percent of mothers but slightly more (36.5 percent) of non-mothers. Differences on the next higher rank 4 also show that the proportion of women without children is higher, 11.2 percent compared to 8.6 percent. It is extremely rare to be on ranks 5 and 6 in the entry job, as less than 1 percent are on these positions. Taken together, these statistics do suggest that women younger than 30 are more likely on lower positions if they have children.

These differences could be related to human capital characteristics. We could observe such a pattern if mothers invest less in education. It could also be that mothers in the entry sample are younger. When we look at the mean age of the two groups we find that mothers are actually slightly older than women without children within the same rank. The age difference is largest on ranks 1 and 2. We also note that mothers have at the mean a higher number of years of education than non-mothers. This holds on every rank except for ranks 1 and 2 where the years of education for mothers are lower. On ranks 1 and 2 are workers who work in unskilled clerical and technical jobs so that it makes a lot of sense that relatively low education may be compensated for by years of (potential) work experience, as we see for mothers. Despite the fact that mothers and non-mothers on the same rank differ with respect to years of education and age, the most frequent occupation for the two groups within rank are the same. Note that on all ranks there are 2 to 6 different occupations, except for rank 5 where there is only one. When we take into account differences in characteristics between nonmothers and mothers, we also confirm that mothers are entering the career ladder on a lower rank than non-mothers (see Appendix Table A1 where we report the results from an ordered probit regression for entry rank). 


\subsection{The decomposition of the family gap in career progression}

\section{The dummy variable approach}

In order to estimate the family gap in career progression we use as the outcome our measure of overall promotions. The variable takes the value 1 if for the person in a given year the rank variable increases by at least 1 unit from year to year. It takes the value zero otherwise. This means that we count all promotions within the same establishment as well as in connection with an establishment change. In Table 3 we present the estimates from a linear probability model. ${ }^{13}$ Column 1 in Table 3 reports the unconditional difference. In columns 2 to 5 we report the results from regressions where we sequentially add a set of control variables holding constant individual differences as well as establishment characteristics.

The raw mother-non-mother difference is the coefficient of the dummy variable, which is 1 if the person is a mother, or has at least one child. The difference is negative and significant. Since this is a simple linear probability model we interpret the coefficient as a difference of 1.6 percentage points (column 1). The average promotion probability among women is 6.3 percent (Table 1$)$ and therefore the raw family gap is 25 percent [(1.6/6.3)*100]. Differences in the distribution across ranks and years do not change this finding. Note, that the regression controls for characteristics in the year before the outcome promotion is measured, which is essentially a first difference in rank. This implies that the rank variable among the explanatory variables always measures the rank the woman is starting from. This is slightly different from the entry rank we looked at in Table 2. We seem however not to confirm the conjecture that differences in entry ranks of mothers and non-mothers contribute a lot to the family gap. The productivity related characteristics age, education, tenure, experience and part time work account for 37.5 percent of the total gap [(0.016-

\footnotetext{
${ }^{13}$ We also estimate a logit model which gives qualitatively and quantitatively similar results. The results are available on request.
} 
0.01)/0.016*100]. When we add in establishment fixed specific effects the explained part increases slightly more.

These results show that the family gap in career progress exists but differences in observed individual characteristics contribute to those differences. Part of these differences accrues indirectly to having children. These factors are parental leave that reduces experience and tenure, and part time jobs that women often work in post-childbirth. Establishment fixed effects may matter significantly if establishments differ, for example, in terms of familyfriendly policies. Since the point estimate does not change significantly when we control for establishment fixed effects, sorting into establishments seems to matter little. Hence, one interpretation of these results is that mothers do not work in establishments that offer careers with less promotion opportunities, which we may often expect from more family friendly establishments.

\section{The Oaxaca-Blinder (O-B) decomposition of the family gap}

The regression results discussed so far simply estimate the family gap by a dummy variable approach and differences in returns to characteristics are not taken into account. In the next step we want to allow for such differences and decompose the family gap in career progress into an explained part due to observed endowments and into an unexplained part (the residual) due to differences in coefficients by estimation of the Oaxaca-Blinder (O-B) decomposition (Oaxaca, 1973; Blinder, 1973). In the first step, we estimate linear promotion regressions separately for mothers and non-mothers. The estimated coefficients are then used to estimate the explained part and the residual or unexplained part. The results of the decomposition are presented in Table 4. As weights the estimated coefficients for nonmothers are used.

Panel 1 in Table 4 presents the decomposition results using our full sample. Column 1reports the absolute accumulated contribution of differences in endowments when we only 
control for rank, year and industry. Even though we saw that mothers and non-mothers are quite differently distributed across ranks at entry, the contribution to the explanation of the raw family gap is now not significant and the total contribution is close to zero. In column 2 we add to the set of explanatory variables age and education. We now can explain 0.003 of the total gap by differences in these characteristics. That is within rank and industry. Keeping in mind that the raw family gap is $0.016,18$ percent of the total gap can now be explained. In column 3 we add variables measuring actual work experience, tenure, and whether someone worked part-time. The explained part becomes approximately twice as high. In terms of the raw family gap, 37 percent can now be explained. Hence, the more flexible decomposition shows that almost 40 percent of the observed family gap in career progression can be explained by differences in characteristics between non-mothers and mothers. Because women with children have lower mean values in those characteristics they did not progress as likely as non-mothers on the career ladder. Critical is that the decomposition also shows that 60 per cent is unexplained by the differences in endowments. It is difficult to tell what exactly causes differences in the coefficients. In a descriptive sense it means that women with children gain less in terms of an increase of the likelihood to be promoted from, for example, an additional year of experience. These differences in estimated coefficients are difficult to interpret $^{14}$ and in the simple O-B decomposition they may result from omitted variable bias. An example for an omitted factor is effort. Women with children may reallocate effort from work to home which reduces the return to experience per year. Differences in coefficients may also result from statistical discrimination.

\footnotetext{
${ }^{14}$ This is an important problem that has long been noted and discussed in the literature on the decomposition of gender wage gap. See e.g. Polachek (1975).
} 


\subsection{The effect of children on career progression}

In this section we want to investigate the effect of years since first childbirth on overall career progress. In Table 5a we present estimation results for our main outcome variable overall promotions. For comparison, we also report results in Table 5b when we use earnings.

We estimate from linear promotion regressions the effect of years since first childbirth where we break up years into year at birth, 1-2 years since childbirth, 3-4 and 5 and more years since childbirth. Column 1 presents the base estimate. In the other columns control variables are added. First, the control variables include a quadratic in age, years of education and cohort-year fixed effects. Then, we add a dummy variable for part-time work and establishment fixed effects. Finally, we add individual fixed effects and rank-year fixed effects. To test robustness of our results we also add in alternative specifications establishment fixed effects and rank-year fixed effects.

The main finding is that women after childbirth are less likely to be promoted than women without children. Specification 1 shows that the effect controlling for the basic characteristics is 3 percentage points during the immediate year after childbirth then decreases to 2.1 to 2.5 percentage points 1 to 4 years after childbirth and 1.8 percentage points per year 5 years or more after childbirth. Controlling for part-time work, specification 2, does not change this finding. This may show that the variable for years since childbirth fully captures related effects already. Controlling for individual fixed effects in the regression, specification 3, absorbs most of the negative longer run effects of entry into motherhood. Now only short run effects of first childbirth are significant and negative. These are the effects for workers with the same education, of the same age and takes also into account cohort-year specific effects. Some of these workers will have further children and we do not account for the exact number of children. Estimates suggest however that the effect works entirely through entry into first motherhood. Specifications 4 and 5 are further robustness checks whether other 
fixed factors can explain the differential effects of years since childbirth. As can be seen, the reported coefficients become again more similar to those in specifications 1 and 2 when we drop individual specific effects and instead control for establishment fixed effects. The same holds when we control for rank-year fixed effects. This shows that factors that are unobserved to us and captured by the individual specific factors are important to understand changes post childbirth.

It could be that women trade career progress for wages. For example, women may change to career tracks that are less likely to lead to a promotion. Therefore, we present for comparison the estimation results when we replace in the above model the outcome variable by hourly earnings. The main finding is that women with children post-childbirth earn less than comparable women without children. Specification 3 in Table 5b reports the individual fixed effect estimate. We find that the effect of years since childbirth is significant and negative and smoothly but moderately increasing from an earnings loss of 0.9 per cent per year to 1.7 percent per year 5 years or more after childbirth. Even though these are moderate earnings losses by international comparison, they are still significant. Overall this shows that women with children lose in terms of promotions and in terms of earnings. The data do not allow us to test whether wage losses are traded for other job characteristics that make those jobs more attractive to women, for example, in terms of work flexibility.

\subsection{Careers over time, and before and after having children}

So far we have investigated the family gap at the mean and after childbirth in the regression analysis. In the following graphical analysis we want to investigate further when the family gap evolves and how it evolves when we follow women over time. In Figure 1 we plot the (unconditional) probability to be promoted by years of work experience for women with and without children separately. 
Figure 1a shows that differences between the groups appear during the early career that is during the first 8 to 10 years in the labor market. When we look at later stages in the careers women with and women without children have equal promotion probability. The graph suggests that this differential is driven by women who become mothers during the first 10 years of their career. Since women in our sample are in their mid to late 20s at the mean at first entry job (Table 2), we do not think that this difference is driven by extremely young mothers. When we split up the sample into those who enter the first job on ranks 1 and 2, versus higher levels then we see that the differential is highly related to the entry rank. This is shown in Figures 1b and 1c. When we look at women who entered ranks above rank 2 then the differential becomes graphically non-significant. This may show that ranks 1 and 2 are lock-in jobs, or may capture other characteristics such as low education. As ranks 1 and 2 are defined, they contain jobs where unskilled or low skilled tasks are performed. Average years of education and age are also lower for workers on those ranks (Table 2).

The figures suggest that the workers on ranks 1 and 2 are different from the remaining workers and that may drive the family gap decomposition results. Therefore we re-estimated the Oaxaca-Blinder decomposition of the family gap dropping workers starting from ranks 1 or 2 . The results are reported in panel 2 of Table 4.

We find that the overall family gap is lower, 0.6 , and amounts to only 42 percent of the raw family gap in the full sample. We find that women with children are relatively better endowed in terms of rank and industry, and therefore these characteristics explain in sum a negative fraction of the total family gap. The explained part increases as we add characteristics to the set of explanatory variables. When we control for the full set of controls we can account for 59 percent of the family gap. This is larger than when we include those workers starting from rank 1 or 2 . However, we still have a significant raw family gap and still 40 percent remain unexplained by the set of controls. 


\section{Conclusions}

In this study we analyzed the question whether women with children are less likely promoted than women without children and, if so, why do we observe these differences. In short, why is there a family gap in career progress? In the process, we investigate when during the life cycle these job promotions occur. For the analysis we use Norwegian data for the period 1987 to 1997. We take into account that women with children may be different from other women in terms of labor market histories. As an extension to the literature we explore to what extent mothers progress more slowly on their career ladders than non-mothers.

Overall, women with children are 22 percent less likely promoted than women without children in our sample period 1987 to 1997. Most compelling is the evidence that work experience, work tenure and part-time work explain a considerable part of the gap. When we control for as many factors as we can, we can explain 37 percent of the total family gap. The explained proportion increases to 59 percent when we focus on those on middle and high ranks. This demonstrates the increased importance of human capital accumulation the higher one is on the career ladder. The results also show that continuous work attachment is important for career progression in the private sector. Hence, women with children fall behind because they work less hours during episodes of their work histories, and have interruptions. Both these factors lead to lower levels of work experience and tenure. Nevertheless, a large part of the family gap remains unexplained.

We find these career advancement differences evolve during one's career. Women with children tend to start lower on the hierarchy than women without children. Differences in the probability to be promoted seem to arise particularly during the first 10 years in the labor market. Some of that seems related to the group of women on the two lowest ranks in the hierarchies of the private sector establishments that we look at. These are typically low or 
unskilled jobs. Possible explanations are selection, if low educated workers are selected into those jobs, or lock-in-effects, if women never manage to exit those low positions because of low work attachment early on during the career, for example, because of interruptions related to childbirths. More research and more extensive data material are needed to investigate this in greater detail.

The evidence we present in this study contributes to the wider literature on differences between mothers and non-mothers in the labor market. So far the literature showed that women with children have lower entry wages than women without children. The results in this study suggest that these may partly be related to differences in entry ranks. Our findings showing that work experience, tenure and full-time work are important determinants of promotions are in line with the evidence in the literature on the family wage gap. Taken together these results suggest that women may forgo important promotions around the period when they have children and this also may have short and longer run effects on their wage paths.

What we learn from the findings of this study is that policies aiming at improving the work - family balance are possibly not only about employment and wages of women. We show that a family gap in career progression exists too and that women with children fall behind on the career ladder if they work part-time or have less work experience. If women with children would close the gap in work experience, tenure and full-time work towards childless women, they would increase the probability to be promoted by 19 percentage points. The gain would be even larger if positioned on middle or high ranks in the career ladder. A policy suggestion we can draw from this evidence is that both policy makers and firms have to become aware that part-time work and work interruptions through parental leave reduces the likelihood to be promoted. This is therefore an additional and important aspect in the debate of why we have so few women in higher rank positions in the private industry. In order 
to explore how widespread it is, it would be interesting to provide a comparative study.

Particularly, it would be interesting to analyze outcomes in countries where the institutions that facilitate the combination of family and work are different.

\section{7. $\quad$ References}

Albrecht, J. W., P.-A. Edin, M. Sundström, S. B.Vroman (1999): Career Interruptions and Subsequent Earnings: A reexamination using Swedish Data, Journal of Human Resources, 34(2), 294-311.

Anderson, D., M. Binder and K. Krause. (2002): The Motherhood Wage Penalty: Which Mothers Pay It and Why?, American Economic Review, 92(2) 354-358.

Angrist, J.D. and W.N. Evans (1998): Children and their parents' labor supply: Evidence from exogenous variation in family size, American Economic Review, 88(3), 450-477.

Bertrand, M., C. Goldin, and L. F. Katz (2010): Dynamics of the gender gap for young professionals in the financial and corporate sectors, American Economic Journal: Applied Economics, 2(3), 228-255.

Blinder, A. S (1973): Wage discrimination: reduced form and structural estimates, Journal of Human resources, 436-455.

Booth, A., M. Francesconi and J. Frank (2003): A sticky floors model of promotion, pay, and gender, European Economic Review, 47, 295-322.

Connolly, S. and Gregory, M. (2008): Moving Down: Women's Part-Time Work and Occupational Change in Britain 1991-2001, Economic Journal, 118(526), F52-76.

Datta Gupta, N. and N. Smith, (2002): Children and Carrer interruptions: The Family Gap in Denmark, Economica, 69, 609-629.

Davies, R. and Pierre, G. (2005): The family gap in pay in Europe: A cross-country study, Labour Economics, 12, 469-86.

Dupuy A. and D. Fernández-Kranz (2011): International differences in the family gap in pay: the role of labour market institutions, Applied Economics, 43(4), 413-438.

Ejrnæs, M., and A. Kunze (2013): Work and wage dynamics around childbirth, The Scandinavian Journal of Economics, 115(3), 856-877.

Felfe, C. (2012): The Motherhood Wage Gap - What about Job Amenities?, Labour Economics, 19, 59-67.

Fitzenberger, B. and A. Kunze (2005): Vocational training and gender: Wages and occupational mobility among young workers, Oxford Review of Economic Policy, 21(3), 392-415.

Francesconi, M. (2001): Determinants and consequences of promotions in Britain, Oxford Bulletin of Economics and Statistics, 63(3), 279--310.

Gibbons, R., and M. Waldman (1999): A theory of wage and promotion dynamics inside firms, Quarterly Journal of Economics, 114(4), 1321-1358.

Goldin C. (2014): A grand convergence: its last chapter, American Economics Review, 104(4), 1091-1119.

Hardøy, I. and P. Schøne (2008): The family gap and family friendly policies: the case of Norway, Applied Economics, 40:22, 2857-2871.

Harkness, S. and Waldfogel, J. (1999): The family gap in pay: evidence from seven industrialized countries, Working Paper No. 219, Centre for Analysis of Social Exclusion, London. 
Heckman, J. J., and J. R. Walker (1990): The Relation between Wages and Income and the Timing and Spacing of Births: Evidence from Swedish Longitudinal Data, Econometrica, 58(6), 1411-41.

Hunnes, A., J. Møen, and K. G. Salvanes (2009): Wage Structure and Labor Mobility in Norway, 1980-97. In The Structure of Wages: An International Comparison. University of Chicago Press, 315-372.

Hotz, V.J., McElroy S.W. and S.G. Sanders (2005): Teenage childbearing andits life cycle consequences: exploiting a natural experiment, Journal of Human Resources, 60(3), 683-715.

Jacobsen, J. P., and L. M. Levin (1995): Effects of intermittent labor force attachment on women's earnings. Monthly Lab. Rev. 118(14).

Jacobsen, J. P., M. Khamis and M. Yuksel (2014): Convergences in Men's and Women's Life Patterns: Lifetime Work, Lifetime Earnings, and Human Capital Investment, IZA Workshop on Gender Convergence, conference paper.

Joshi, H.; P. Paci and J. Waldfogel, (1999): The Wages of Motherhood: Better or Worse?, Cambridge Journal of Economics, 23(5), 543-64.

Kunze, A. and Miller, A.R. (2014): Women helping women? Gender spillover in career progression, available at SSRN: http://ssrn.com/abstract=2472720.

Kunze, A. and K. R. Troske (2012): Life-cycle patterns in male/female differences in job search, Labour Economics , 19.2, 176-185.

Kunze, A. and K. R. Troske (2014): Gender differences in job search among young workers: A study using displaced workers in the US, forthcoming in Southern Economic Journal.

Lundberg, S. and E. Rose (2000): Parenthood and the Earnings of Married Men and Women, Labour Economics, 7(6), 689-710.

Manning, A., \& Petrongolo, B. (2008): The Part-Time Pay Penalty for Women in Britain, Economic Journal, 118(526), F28-51.

Manning, A., and J. Swaffield (2008): The gender gap in early-career wage growth, The Economic Journal, 118(530), 983-1024.

Miller, A.R. (2011): The effects of motherhood timing on career path, Journal of Population Economics, 24(3), 1071-1100.

Mincer, J. and S. Polachek, (1974): Family Investment in Human Capital: Earnings of Women, Journal of Political Economy, 82(2), (supplement), S76-S108.

Nielsen, H. Skyt, M. Simonsen and M. Verner (2004): Does the Gap in Family-friendly Policies Drive the Family Gap?, The Scandinavian Journal of Economics, 106(4), 721744.

Oaxaca, R. (1973): Male-female wage differentials in urban labor markets, International Economic Review, 693-709.

Petersen, T., A. M. Penner and G. Høgsnes (2010): The Within-Job Motherhood Wage Penalty in Norway, 1979-1996, Journal of Marriage and Family, 72(5), 1274-1288.

Phipps, S., P. Burton and L. Lethbridge (2001): In and out of Labour Market: Long-term Income Consequences of Child-Related Interruptions to Women's Paid Work, Canadian Journal of Economics, 34(2), 411-429.

Polachek, S. (1975): Differences in Expected Post School Investment as a Determinant of Market Wage Differentials, International Economic Review, 16(2), 451-70.

Polachek, S. W. (1975): Potential biases in measuring male-female discrimination, Journal of Human Resources, 10(2), 205-229.

Polachek, S. (1981): Occupational Self Selection: A Human Capital Approach to Sex Differences in Occupational Structure, Review of Economics and Statistics, 63(1), 6069. 
Simonsen, M. and L. Skipper (2010): The family gap revisited: What wombmates reveal, Labour Economics, 19, 102-112.

Waldfogel, J. (1998): The Family Gap for Young Women in the United States and Britain: Can Maternity Leave Make a Difference?, Journal of Labor Economics, 16(3), 505-45.

Waldfogel, J. (1998): Understanding the family gap in pay for women with children, Journal of Economic Perspectives, 12(1), 137-156. 
Table 1: Summary statistics, women

\begin{tabular}{lcccc} 
& \multicolumn{2}{c}{ All Women } & Women with children \\
\hline & Mean & Std.dev. & Mean & Std.dev. \\
\hline Individual characteristics & & & & \\
1 if Mother & 0.565 & & 1.000 & \\
Age & 37.20 & 9.49 & 38.40 & 7.80 \\
Years of education & 11.60 & 2.26 & 11.50 & 2.20 \\
Contracted hours of work & 35.20 & 5.70 & 34.20 & 6.60 \\
1 if Part-time work (less than 30 hours of work) & 0.26 & 0.44 & 0.33 & 0.47 \\
Years of experience & 14.50 & 6.78 & 15.60 & 5.80 \\
Years of tenure & 5.76 & 4.57 & 6.00 & 4.52 \\
log(hourly earnings) & 4.54 & 0.23 & 4.56 & 0.23 \\
Rank in the hierarchy (rank 1(low) to 7(top)) & 2.56 & 1.21 & 2.55 & 1.23 \\
1 if overall promotion (all) & 0.063 & 0.243 & 0.056 & 0.230 \\
1 if internal promotion & 0.053 & 0.224 & 0.048 & 0.214 \\
Selected employer characteristics & & & & \\
Employer size & 17.60 & 66.80 & 18.30 & 70.70 \\
Highest rank & 3.00 & 1.40 & 3.00 & 1.46 \\
Lowest rank & 1.60 & 0.90 & 1.60 & 0.90 \\
Number of observations & 211844 & & 119647 & \\
\hline \hline
\end{tabular}




\begin{tabular}{|c|c|c|c|c|c|c|c|c|}
\hline \multirow[t]{2}{*}{ Rank } & \multicolumn{2}{|c|}{$\%$} & \multicolumn{2}{|c|}{ Age } & \multicolumn{2}{|c|}{ Education } & \multicolumn{2}{|c|}{ Most frequent occupation group } \\
\hline & $\begin{array}{c}\text { Non- } \\
\text { mothers }\end{array}$ & Mother & $\begin{array}{l}\text { Non- } \\
\text { mother }\end{array}$ & Mothers & $\begin{array}{l}\text { Non- } \\
\text { mother }\end{array}$ & Mothers & Non-mothers & Mothers \\
\hline 7 (Top) & . & . & . & . & . & . & & \\
\hline 6 & 0.5 & 0.5 & 27.9 & 28.2 & 13.9 & 14.3 & $\begin{array}{c}\text { head of } \\
\text { department }\end{array}$ & $\begin{array}{c}\text { head of } \\
\text { department }\end{array}$ \\
\hline 5 & 0.1 & 0.1 & 27.9 & 29.0 & 15.8 & 16.5 & $\begin{array}{c}\text { chief of } \\
\text { department }\end{array}$ & $\begin{array}{c}\text { chief of } \\
\text { department }\end{array}$ \\
\hline 4 & 11.2 & 8.6 & 26.4 & 27.5 & 12.7 & 13.9 & accountant & accountant \\
\hline 3 & 36.5 & 32.8 & 25.2 & 27.0 & 11.6 & 12.1 & $\begin{array}{c}\text { skilled, account } \\
\text { clerk }\end{array}$ & $\begin{array}{c}\text { skilled, account } \\
\text { clerk }\end{array}$ \\
\hline 2 & 16.8 & 18.1 & 23.6 & 26.8 & 12.3 & 11.6 & various & various \\
\hline 1 (Bottom) & 34.8 & 39.8 & 23.6 & 26.2 & 11.6 & 11.4 & clerical unskilled & clearical unskilled \\
\hline
\end{tabular}

Note: * Entry rank is the first rank observed in the individual time series excluding all observations for those who are older than 30.

Mothers are those with a positive number of children. The entry sample contains 14087 non-mothers and 3992 mothers. 
Table 3: The family gap in career progression (LPM regression results: Binary outcome variable is moving up or not) - Dummy variable estimates

\begin{tabular}{lccccc}
\hline & $\mathbf{1}$ & $\mathbf{2}$ & $\mathbf{3}$ & $\mathbf{4}$ & $\mathbf{5}$ \\
\cline { 2 - 6 } & Coef (s.e.) & Coef. (s.e.) & Coef (s.e.) & Coef. (s.e.) & Coef.(s.e.) \\
\hline 1 if Mother & -0.016 & -0.016 & -0.013 & -0.010 & -0.009 \\
& $(0.0013)^{* * *}$ & $(0.0013)^{* * *}$ & $(0.0012)^{* * *}$ & $(0.0013)^{* * *}$ & $(0.0013)^{* * *}$ \\
Rank, Year and Industry fixed effects & No & Yes & Yes & Yes & Yes \\
Age, Education & No & No & Yes & Yes & Yes \\
Experience, Tenure, Part-time Work & No & No & No & Yes & Yes \\
Establishment fixed effect & No & No & No & No & Yes \\
Number of observations & 211844 & 211844 & 211844 & 211844 & 211844 \\
R-squared & 0.001 & 0.025 & 0.039 & 0.041 & 0.052 \\
\hline \hline Note. Reported standard errors are clustered at the establishment-year-individual level. ${ }^{*} p<0.05, * * p<0.01$, \\
$* * *$ p $<0.001$
\end{tabular}




\begin{tabular}{|c|c|c|c|c|c|c|}
\hline & \multicolumn{2}{|c|}{1} & \multicolumn{2}{|l|}{ 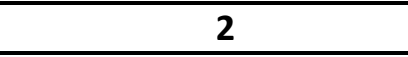 } & \multicolumn{2}{|c|}{3} \\
\hline & $\begin{array}{c}\text { Absolute } \\
\text { contribution }\end{array}$ & z-value & $\begin{array}{c}\text { Absolute } \\
\text { contribution }\end{array}$ & z-value & $\begin{array}{c}\text { Absolute } \\
\text { contribution }\end{array}$ & z-value \\
\hline \multicolumn{7}{|l|}{ Panel1: Decomposition for the base sample } \\
\hline Raw Difference & 0.0161 & & 0.0161 & & 0.0161 & \\
\hline Endowment (total) & -0.0005 & -1.32 & 0.0028 & 3.82 & 0.0060 & 7.85 \\
\hline Coefficient (total) & 0.0167 & 13.49 & 0.0133 & 10.89 & 0.0100 & 8.01 \\
\hline Percentage explained & $0 \%$ & & $18 \%$ & & $37 \%$ & \\
\hline Number of Observations & 211844 & & 211844 & & 211844 & \\
\hline \multicolumn{7}{|c|}{ Panel 2: Decomposition for the sample that excludes those on ranks 1 and 2} \\
\hline Raw Difference & 0.0068 & & 0.0068 & & 0.0068 & \\
\hline Endowment (total) & -0.0016 & -4.12 & 0.0002 & 0.25 & 0.0020 & 2.39 \\
\hline Coefficient (total) & 0.0084 & 5.59 & 0.0066 & 4.52 & 0.0040 & 3.19 \\
\hline Percentage explained & $-23 \%$ & & $3 \%$ & & $59 \%$ & \\
\hline Number of observations & 114644 & & 114644 & & 114644 & \\
\hline \multicolumn{7}{|l|}{ Explantory variables: } \\
\hline Rank fixed effects & $x$ & & $X$ & & $\mathrm{X}$ & \\
\hline Year fixed effects & $\mathrm{X}$ & & $X$ & & $\mathrm{X}$ & \\
\hline Industry fixed effects & $x$ & & $x$ & & $x$ & \\
\hline Age fixed effects & & & $x$ & & $x$ & \\
\hline Education fixed effects & & & $x$ & & $x$ & \\
\hline Years of experience (squared) & & & & & $x$ & \\
\hline Yrs of tenure (squared) & & & & & $x$ & \\
\hline Part-time work (less than 37 hours per week) & & & & & $\mathrm{x}$ & \\
\hline Number of observations & 211844 & & 211844 & & 211844 & \\
\hline
\end{tabular}

Note: Linear promotion regressions are estimated in the first stage separately for non-mothers and mothers. For the decomposition the coefficients from the non-mother regression are used as weights. 
Table 5a: Impact of years since the birth of first child on the promotion probability of females

\begin{tabular}{|c|c|c|c|c|c|c|c|c|c|c|}
\hline & \multicolumn{2}{|c|}{1} & \multicolumn{2}{|c|}{2} & \multicolumn{2}{|c|}{3} & \multicolumn{2}{|c|}{4} & \multicolumn{2}{|c|}{5} \\
\hline & Coef. & (s.e.) & Coef. & (s.e.) & Coef. & (s.e.) & Coef. & (s.e.) & Coef. & (s.e.) \\
\hline \multicolumn{11}{|l|}{ Year after birth of first child } \\
\hline immediate & -0.030 & $(0.004)$ & -0.030 & $(0.003)$ & -0.016 & $(0.004)$ & -0.029 & $(0.004)$ & -0.032 & $(0.004)$ \\
\hline 1 or 2 & -0.025 & $(0.003)$ & -0.024 & $(0.003)$ & -0.008 & $(0.004)$ & -0.024 & $(0.004)$ & -0.028 & $(0.003)$ \\
\hline 3 or 4 & -0.021 & $(0.004)$ & -0.020 & $(0.004)$ & 0.001 & $(0.005)$ & -0.020 & $(0.004)$ & -0.025 & $(0.004)$ \\
\hline 5 or more & -0.018 & $(0.002)$ & -0.018 & $(0.002)$ & 0.008 & $(0.007)$ & -0.016 & $(0.002)$ & -0.023 & $(0.002)$ \\
\hline Part-time work (less than 37 hours per week) & No & & Yes & & No & & No & & No & \\
\hline Person fixed effects & No & & No & & Yes & & No & & No & \\
\hline Establishment fixed effects & No & & No & & No & & Yes & & Rank-Year & ed effects \\
\hline R-squared & 0.02 & & 0.02 & & 0.19 & & 0.21 & & 0.05 & \\
\hline Number of observations & 211844 & & 211844 & & 211844 & & 211844 & & 211844 & \\
\hline
\end{tabular}

Table 5b. Impact of years since the birth of first child on the hourly earnings of females

\begin{tabular}{|c|c|c|c|c|c|c|c|c|c|c|}
\hline & \multicolumn{2}{|c|}{1} & \multicolumn{2}{|c|}{2} & \multicolumn{2}{|c|}{3} & \multicolumn{2}{|c|}{4} & \multicolumn{2}{|c|}{5} \\
\hline & Coef. & (s.e.) & Coef. & (s.e.) & Coef. & (s.e.) & Coef. & (s.e.) & Coef. & (s.e.) \\
\hline \multicolumn{11}{|l|}{ Year after birth of the first child } \\
\hline immediate & -0.010 & $(0.002)$ & -0.010 & $(0.002)$ & -0.009 & $(0.001)$ & -0.007 & $(0.002)$ & -0.012 & $(0.002)$ \\
\hline 1 or 2 & -0.003 & $(0.002)$ & -0.002 & $(0.002)$ & -0.011 & $(0.001)$ & -0.003 & $(0.002)$ & -0.004 & $(0.002)$ \\
\hline 3 or 4 & -0.001 & $(0.003)$ & 0.000 & $(0.003)$ & -0.014 & $(0.001)$ & -0.004 & $(0.003)$ & -0.001 & $(0.002)$ \\
\hline 5 or more & -0.026 & $(0.001)$ & -0.026 & $(0.001)$ & -0.017 & $(0.002)$ & -0.015 & $(0.001)$ & -0.015 & $(0.001)$ \\
\hline Part-time work (less than 37 hours per week) & No & & Yes & & No & & No & & No & \\
\hline Person fixed effects & No & & No & & Yes & & No & & No & \\
\hline Establishment fixed effects & No & & No & & No & & Yes & & Rank-Yea & red effects \\
\hline R-squared & 0.46 & & 0.46 & & 0.96 & & 0.68 & & 0.66 & \\
\hline Number of observations & 211844 & & 211844 & & 223829 & & 211844 & & 223829 & \\
\hline
\end{tabular}

Note: All regressions control for (year*cohort) dummy variables, age and age squared and dummy variables for years of education. 
Figure 1a: Unconditional probability to be promoted (overall promotions)

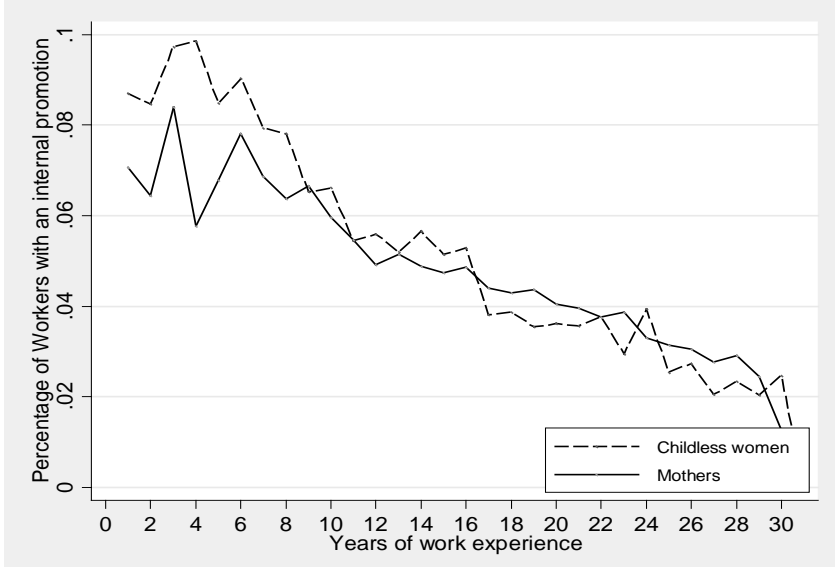

Figure 1b: Unconditional probability to be promoted (overall promotions) if starting rank 1 or 2

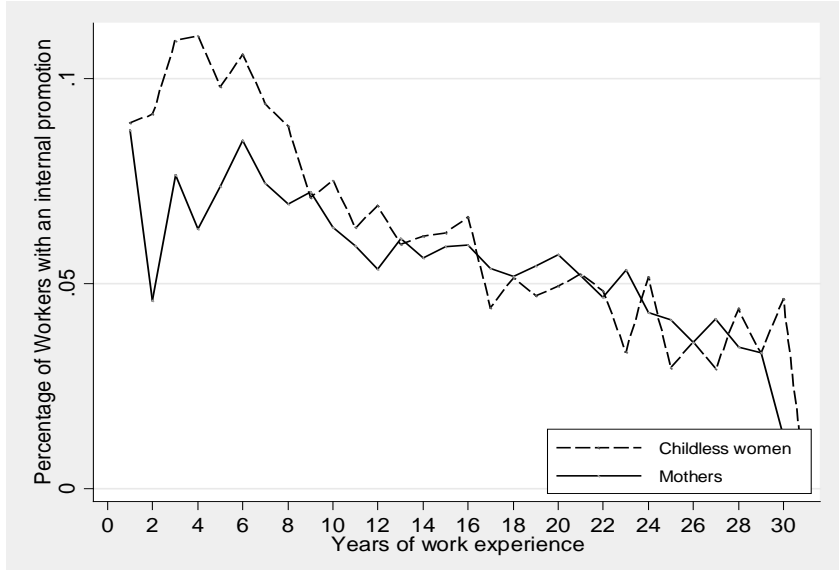

Figure 1c: Unconditional probability to be promoted (overall promotions) if starting rank 3 and above

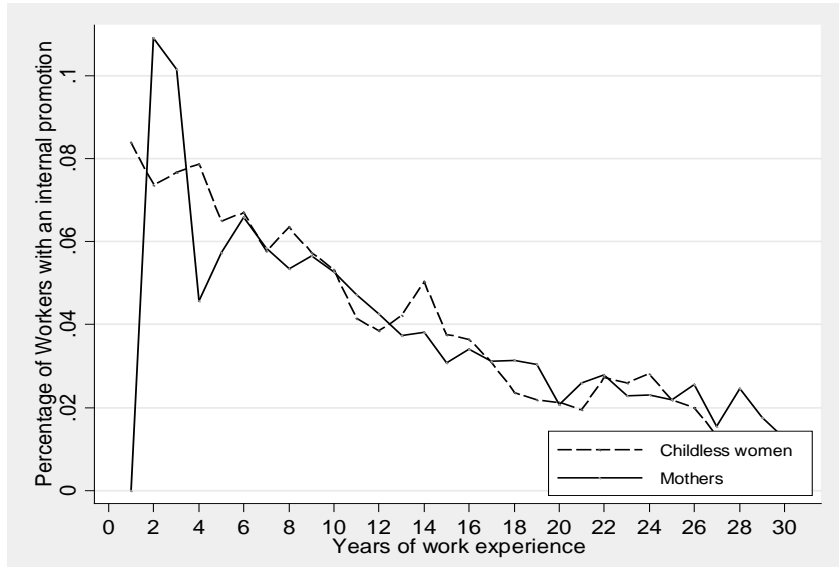


Appendix Table A1: Ordered probit regressions for entry rank

\begin{tabular}{lccc}
\hline & Coef (s.e.) & Coef. (s.e.) & Coef (s.e.) \\
\hline 1 if Mother & -0.15 & -0.23 & -0.22 \\
& $(0.02)$ & $(0.02)$ & $(0.02)$ \\
Industry + Year Fixed Effects & Yes & Yes & Yes \\
Age, Education & No & yes & Yes \\
Exp., Tenure, Part-Time & No & No & Yes \\
Number of observations & 18079 & 18079 & 18079 \\
R-squared & 0.01 & 0.10 & 0.11 \\
\hline \hline
\end{tabular}

Note: Entry rank can take the value 1(lowest rank) to 7 (top rank).

Coefficients and standard errors are reported. 